\title{
As ações desencontradas da política ex- terna do Brasil frente à Argentina (1951- 1954) ${ }^{1}$
}

\author{
The mismatched actions of Brazil's foreign policy \\ vis-à-vis Argentina (1951-1954)
}

\section{Ana Luiza Setti Reckziegel²}

Resumo: $O$ artigo aborda as ações dos agentes estatais brasileiros no que se refere às relações com Argentina, durante os governos de Getúlio Vargas (1951-1954) e Juan Domingo Perón (1950-1955). As duas abordagens disputaram a primazia na definição do viés da política externa: a presidencial, que encaminhava a aproximação com a vizinha Argentina, e a do Ministério das Relações Exteriores, permeada por tensões e divergências no nível intra diplomático. Para a compreensão desse cenário, uma variável de análise importante foi a política interna brasileira, na qual concorriam grupos tanto a favor quanto contra a aproximação bilateral. Outra variável de análise foi a influência dos Estados Unidos, que estiveram atentos a todas as negociações de integração, contrários que eram à formação de blocos regionais no âmbito do subsistema de poder americano.

Palavras-chave: Política Externa; Relações Internacionais; Política Interna; Blocos Regionais.

Abstract: This article aims to address the actions of Brazilian state agents regarding relations with Argentina during the governments of Getúlio Vargas (1951-1954) and Juan Domingo Perón (1950-1955). Two aproaches disputed the primacy in defining the way of foreign policy towards Argentina: the presidential one, which advocated for the rapprochement between the two countries, and that of the Ministry of Foreign Relations, permeated by tensions and divergences on an intradiplomatic level. To understand this scenario, an important analysis variable was Brazilian domestic politics, in which there were groups that manifested both in favour and against the initiative to bring the nations closer together. Another variable was the influence of the United States, which were attentive to all integration negotiations, contrary to the formation of regional blocs under the American subsystem of power as they were.

Keywords: Foreign Policy; International Relations; Internal Policy; Regional Blocks.

\footnotetext{
DOI: https://doi.org/10.24215/23142766e062

${ }^{1}$ Recibido: 16/04/2019. Aceptado: 02/07/2019

2 Doutora em História Ibero-Americana. Professora titular do curso de graduação em História e do Programa de Pós-Graduação em História da Universidade de Passo Fundo (UPF), Brasil. email: analuiza@upf.br
} 


\section{Considerações Iniciais}

Esse artigo tem como objetivo analisar as estratégias usadas pelos agentes estatais brasileiros na condução da política externa frente à Argentina entre 1951 e 1954. O desenrolar das relações bilaterais levou à constatação de que as percepções desses agentes sobre a forma de aproximação com o país vizinho foram desencontradas e, mais do que isso, divergentes, a ponto de fragilizar a política externa do país. Quais teriam sido os fatores que levaram à divergência entre o presidente Vargas e seu ministro João Neves da Fontoura e entre esse e o embaixador Batista Lusardo? Teria sido a política interna? Ou teria sido a ação dos Estados Unidos, país líder do sistema americano de poder, que refutava a ideia de formação de blocos regionais? Tentaremos, ao longo do artigo, contextualizar essas questões.

À temática em questão é interessante agregar algumas considerações de cunho teórico. Iniciamos refletindo que o cruzamento da História Política com as Relações Internacionais no contexto analisado tem significativa importância para o entendimento das diretrizes norteadoras da política interna brasileira e aportou elementos essenciais para compreender a estratégia adotada pelo presidente Vargas na condução da política externa. Quando se analisam as relações internacionais de um país, há que se identificar, em primeiro lugar, as partes. De acordo com Robert Wendzel (1985), existem dois tipos de participantes: os Estados e os atores não estatais. A historiografia tem destinado grande parte da atenção ao estudo do primeiro e será também o caso da abordagem desse artigo. Isto é, a análise terá como foco os atores estatais e no contexto das disputas pela proeminência política no âmbito político sul-americano, o país que confrontou o Brasil naquele momento foi a Argentina, historicamente concorrente pela liderança regional.

No âmbito conceitual, Relações Internacionais constitui um campo acadêmico de conhecimento interdisciplinar que estuda as relações internacionais como um dado empírico. De acordo com Williams Gonçalves, a ambiguidade é que as Relações Internacionais estudam as relações internacionais. Isto é, a disciplina e a realidade que essa disciplina busca conhecer têm o mesmo nome. Para contornar essa ambiguidade e, dessa forma, possibilitar o entendimento do discurso, os estudiosos convencionaram diferenciar o nome da disciplina do nome do objeto mediante o uso de iniciais maiúsculas para a primeira, Relações Internacionais, e de iniciais minúsculas para o objeto do conhecimento, relações internacionais, (Gonçalves, 2011:7).

Como aponta o historiador Estevão de Rezende Martins, (2012:90) trata-se de um campo do conhecimento que, a despeito de sua autonomia, é marcado por uma profunda interdisciplinaridade, influenciado pelo direito, pela economia, pela história, pela ciência política, assim como por outros saberes. No Brasil, a renovação metódica e inovação temática da pesquisa em relações internacionais desde a década de 1980 superou os paradigmas prevalecentes nos Estados Unidos. No lugar da segurança e dos conflitos armados ganhou proeminência a questão do desenvolvimento e autonomia econômica e as relações regionais foram objeto de pesquisas ampliadas. Parafraseando Estevão Martins, as relações internacionais são, pois, um campo de estudos autônomo, caracterizado pela pluralidade de orientações teóricas que dialogam entre si em meio às viragens e continuidades das análises das relações internacionais, destaca-se que seu objeto se deslocou gradativamente das relações eurocêntricas, ou euro-americanas, e passou a lidar com as diversas áreas do mundo. 
O campo da história das relações internacionais constitui o locus em que o longo prazo dos processos e de seus desdobramentos prima sobre o mero registro das ocorrências isoladamente e, também, o campo do mundo político, no qual tem lugar a reação dos povos à conformação de suas instituições internas e dos atos de seus protagonistas políticos a partir de suas necessidades (reais ou interpretadas) de seus valores, de suas prioridades e de suas preferências. Nele, aparecem também as reações das sociedades quando se contrapõem a outras e projetam olhar e experiência para além de suas fronteiras. $O$ trabalho dos historiadores reflete essa pesquisa de múltipla face (Martins, 2012: 90).

Um dos fatores que compõem as relações internacionais é a política externa ${ }^{3}$. Sendo mediante a sua formulação, que o Estado define as prioridades, expectativas e alianças para atuar no quadro das relações internacionais (Gonçalves, 2011:7). Os trabalhos dos cientistas políticos, como Raymond Aron, e de sociólogos, como Marcel Merle, levaram à história política a também se debruçar sobre pesquisas que articulavam o que se passavam "do lado de dentro e o ambiente internacional, entre as escolhas de política interna e as que se supõe ligadas aos assuntos externos" (Milza, 1996: 366).

O postulado de que não há diferença de natureza, tampouco separação estanque entre o interior e o exterior, mas interações evidentes entre um e outro, com, entretanto, uma primazia reconhecida do primeiro sobre o segundo, que muitos representantes da escola francesa de história das relações internacionais colocaram, explicitamente ou não, no centro de sua problemática, decorre que os historiadores do "político" e historiadores "internacionalistas" têm em comum um imenso repertório de pesquisa e de reflexão onde se pode, efetuar avanços paralelos (Milza,1996: 370).

Dentre as variáveis que influenciam as relações internacionais, Jean- Baptiste Duroselle considera a política interna dos Estados como uma das principais chaves de explicação do jogo internacional. Para esse autor, não existe nenhum ato político exterior que não tenha um aspecto de política interna. Todo ato que visa ao exterior tem um aspecto interno e, portanto, toda teoria das relações internacionais implica um estudo aprofundado da política interna (Duroselle, 2000: 56-59).

A escola francesa da história das relações internacionais fez do tema da "política interna", tomada no sentido lato, um dos pivôs de sua problemática. ${ }^{4}$ Pierre Milza, aponta que as relações entre a chamada política interna dos Estados e os relacionamentos que estes mantêm com as outras unidades políticas que estruturam o sistema internacional constituem um campo de pesquisa e reflexão em que se cruzam com uma frequência cada vez maior os métodos e os trabalhos provenientes de duas "escolas": a da história "política", propriamente dita, e a das relações internacionais contemporâneas. (Milza, 1996: 365)

É fato que, no decorrer do segundo governo Vargas, duas abordagens disputaram a primazia na definição do viés da política externa: a presidencial, que encaminhava a aproximação com a vizinha Argentina, e a do Ministério das Relações Exteriores, permeada por tensões e divergências no nível intra diplomático ${ }^{5}$. Para fins desse estudo, é fundamental

\footnotetext{
${ }^{3}$ Sobre o tema da política externa, ver: RUSSEL, Roberto (1992). Enfoques teóricos y metodológicos para el estudio de la política exterior. Buenos Aires: GEL.

${ }^{4}$ Ver especialmente as obras de René Girault e Robert Frank (1984) La puissance em Europe (1938-1940). Paris: Publications de la Sorbone..

${ }^{5}$ Por intra diplomático entendemos o que ocorre no âmbito das chancelarias.
} 
aludir à política interna para demonstrar que os conflitos entre os agentes que conduziram a política externa não deixaram de ser influenciados pela variável doméstica.

\section{Relações internacionais no sul da América}

A década de 1950 se apresentou, para as relações Brasil-Argentina, como de aparente simetria. De um lado, os dois países passaram a dispor dos requisitos básicos que lhes permitiram rápidos processos de industrialização. Apesar de manterem fortes vínculos de dependência com o sistema econômico internacional, tanto Brasil como Argentina foram capazes de realizar um processo de substituição de importações, durante os anos trinta, que, ao ser mantido a longo prazo, poderia conduzir a uma transformação estrutural de suas economias. Por outro lado, ambos se viram, diretamente ou não, envolvidos na inserção da América Latina em um projeto político internacional (HIRST, 1985). No que se refere aos contextos políticos, a orientação trabalhista e a estrutura obrera, embora consideradas suas particularidades, parecia também aproximá-los. Vargas se dirigia aos "trabalhadores do Brasil" e Perón era chamado "o primeiro trabalhador" ${ }^{6}$. Evidentemente, essa similitude político-ideológica dos governos Vargas e Perón, não significou, de forma alguma, o abandono de uma postura competitiva entre as duas nações. ${ }^{7}$

Ao lado dessas semelhanças havia, entretanto, diferenças que poderiam ser localizadas na condução das respectivas políticas externas. Apesar disso, essa identificação inicial acabou por estimular a melhoria das relações argentino-brasileiras, significativamente comprometidas no governo do general Eurico Gaspar Dutra (1946-1950) ${ }^{8}$. O momento de maior significado desse novo contexto seria a formulação de uma proposta integracionista, configurada no que ficou conhecido por Pacto $A B C$, uma reedição adaptada do $A B C$ de Rio Branco, agora uma proposta de integração econômica e política entre Argentina, Brasil e Chile. Era, na verdade, nada mais do que a expressão da política peronista de formação de blocos regionais que se contrapusessem à potência hegemônica central, os Estados Unidos. ${ }^{9}$

Essa proposição de formação de blocos regionais estava coadunada com o que ficou conhecido como a Terceira Posição. Ainda que tenha sofrido variações de escala e força em nível mundial e no âmbito regional e nacional, a política exterior argentina durante a década peronista pode ser caracterizada como o intento de definir a inserção internacional do país, no mundo bipolar criado pela Guerra Fria, através da chamada Terceira Posição, pela qual

\footnotetext{
${ }^{6}$ Sobre essa questão ver FAUSTO, Boris e DEVOTO, Fernando J. (2004) Brasil e Argentina. Um ensaio de história comparada (1850-2002) São Paulo: Editora34, p. 328.

${ }^{7}$ Sobre a política externa de Perón, ver: RUIZ MORENO, Isidoro (1961). História de las relaciones exteriores argentinas, 1810-1955. Buenos Aires: Perrot; CONIL PAZ, A; FERRARI, G. E. (1962) Política exterior argentina,1930-1962. Buenos Aires: Huemul CAFIERO, A. (1996). La política exterior peronista, (1946-1955). El mito aislacionista. Buenos Aires: Corrigedor; REIN, Raanan (1998). Peronismo, populismo y política. Argentina 1943-1955. Buenos Aires: Editorial de Belgrano; JALABE, S. R. (comp.) (1996) La política exterior argentina y sus protagonistas,1880-1995. Buenos Aires: Cari/ Gel.

${ }^{8}$ Ver: VIZENTINI, Paulo G. Fagundes (2003). Do nacional-desenvolvimentismo à Política Externa Independente (1945-1964). In FERREIRA, Jorge e DELGADO, Lucília de Almeida Neves (orgs). O Brasil republicano. O tempo da experiência democrática, Rio de Janeiro: Civilização Brasileira, p. 195-216.

${ }^{9}$ Sobre o Pacto ABC, visto da perspectiva brasileira, conferir: RECKZIEGEL, Ana Luiza Setti. O Pacto ABC. As relações Brasil-Argentina na década de 1950. Passo Fundo: Ediupf, 1996.
} 
pretendia balancear o peso considerável dos Estados Unidos, procurando um maior protagonismo na América Latina, consolidando a tradicional conexão com a Europa e estabelecendo laços diplomáticos com o bloco soviético, ainda esse último não significasse abandonar a ligação com o Ocidente (Rapoport, 2002).

Não só o histórico de rivalidade entre Brasil e Argentina impunha dificuldades para a concretização do $A B C$ peronista. O Pacto, no âmbito brasileiro, acirrou as controvérsias e teve significativas repercussões para o governo Vargas, nas quais estavam contidas, além do velho conflito pela supremacia sul-americana, o próprio germe das dissensões internas: o alinhamento incondicional aos Estados Unidos ou a busca por uma autonomia relativa no âmbito do sistema de poder capitalista.

Se havia consenso a respeito da necessidade de o Brasil impor-se como liderança regional, as formas de encaminhamento da questão variaram no próprio âmbito do poder executivo, em evidente discordância entre o presidente Vargas e seu ministro das Relações Exteriores, João Neves da Fontoura. Por sua vez, nem ao menos no Ministério das Relações Exteriores havia consenso sobre a estratégia a ser adotada pelo Brasil a fim de se afirmar como país líder na região, o que revelava um sério conflito intra diplomático. Esse foi o caso da grave dissonância entre o ministro Neves da Fontoura e o embaixador na Argentina, Batista Lusardo. O cerne do desacordo entre a linha do ministro e do embaixador residia na esfera do encaminhamento do protagonismo brasileiro. Isto é, se deveria ser pleiteado frente à nação hegemônica do sistema, os Estados Unidos, ou em nível dos países sul-americanos. O movimento para obtenção da liderança regional esteve vinculado a uma conjuntura que incluía, de um lado, as manifestações peronistas em pro do pan-latinismo, que encontrou no embaixador Lusardo um defensor, e, de outro, a pressão dos Estados Unidos pelo pan-americanismo, posição defendida pelo ministro Neves da Fontoura.

\section{Interações entre política interna e política externa}

De acordo com Estevão Martins, dentre os eixos principais de reflexão elaborada no Brasil, dos anos 1990 em diante, estão as relações entre política interna e política externa e a busca da estruturação e consolidação de uma posição de liderança do país no âmbito regional (Martins, 2012:86). Partindo dessa premissa, tentaremos demonstrar as condições nas quais se desenrolava a política interna brasileira nesse período a fim de estabelecer as articulações que foram, ou não, possíveis de estabelecer no âmbito externo.

Quando Getúlio Vargas (1882-1954) retornou ao poder em 1951, como presidente constitucional eleito pelo voto popular, voltou-se para uma questão que considerava fundamental para o sucesso de sua administração: o desenvolvimento da industrialização. Para isso precisava contar com o auxílio dos empréstimos estrangeiros, visto que o Brasil não dispunha de condições para arcar com os investimentos necessários a esta empreitada. ${ }^{10}$

As dificuldades referentes à política econômica foram encaradas por Vargas de forma ambivalente: de um lado aceitava as regras tradicionais do sistema internacional e procurava adequar-se a elas, e de outro estimulava uma postura nacionalista, não tendo sido raras

\footnotetext{
${ }^{10}$ Ver: FONSECA, Pedro Cesar Dutra. Vargas: o capitalismo em construção (1906-1954). São Paulo: Brasiliense, 1989.
} 
as vezes em que atacou o capital estrangeiro, condenando, por exemplo, a remessa de lucros para fora do país.(Skidmore: 1982)

Por seu turno, os Estados Unidos estavam pouco interessados em fomentar o desenvolvimento de nações periféricas. Com o intuito de obter estes empréstimos, Vargas se apoiava no próprio espaço criado pela Guerra Fria e defendia uma política de relativa reciprocidade com os Estados Unidos no seguinte sentido: os norte-americanos liberariam os empréstimos necessários ao projeto de desenvolvimento econômico de Vargas e este se manteria fiel à proposta pan-americanista.

Conforme aponta Leandro Morgenfeld (2011), a ajuda econômica que a América Latina esperava dos Estados Unidos foi exígua e acabou frustrando as pretensões de ser incluída no Plano Marshall. Entre 1945 e 1952, a região recebeu menos assistência econômica do que a Bélgica e Luxemburgo. E desse total geral, o Brasil concentrou mais da metade do valor de um milhão e trezentos mil dólares, o que estava aquém das necessidades do país.

Ainda de acordo com Morgenfeld, "apenas se outorgaram créditos limitados, através do Eximbank, que era uma forma de subvencionar as exportações e as importações privadas dos Estados Unidos para a região e, desde estão não houve empréstimos para as empresas estatais latino-americanas, para não favorecer o nacionalismo econômico e nem o estatismo, considerados os males da época na América Latina" (2011:352).

O entrave nas negociações dos empréstimos levou Vargas a adotar como estratégia de pressão sobre os Estados Unidos, a possibilidade do aprofundamento da aproximação com a Argentina, a qual defendia para os países periféricos uma maior autonomia de ação no sistema internacional de poder através da formação de blocos regionais independentes.

Procurando esclarecer a posição brasileira a fim de evitar equívocos, logo nos primeiros meses de governo, Neves da Fontoura foi em missão conversar com o Secretário de Estado norte-americano, Miller. A decorrência dessas conversações foi a promessa de abertura de um crédito na ordem de US\$ 250 milhões, menos da metade requisitada pelo ministro da Fazenda, Lafer, mas o suficiente para animar o ministro Neves. (Reckziegel, 1996)

Na verdade, explicitavam-se duas situações: se, por um lado, tentava-se evitar uma associação direta entre a posição brasileira no sistema de poder e a cooperação econômica externa, por outro lado, não havia como desconectar uma coisa da outra. Decorrente disso, a apreensão de Neves de que uma definição pró Perón viesse a prejudicar o projeto desenvolvimentista brasileiro, numa ocasião em que qualquer entrave à aceleração do desenvolvimento econômico significaria, também, o enfraquecimento da oportunidade da realização da liderança regional.

A forma de agir do presidente Vargas, que encetava uma espécie de jogo duplo frente à Argentina e aos Estados Unidos, provocou imediata reação no âmbito do governo brasileiro. Uma das primeiras manifestações ocorreu quando o ministro das Relações Exteriores, João Neves da Fontoura (1887-1963), exonerou-se, no final de junho de 1953. Defensor do que chamava de pan-americanismo solidário, Neves da Fontoura insistia num alinhamento incondicional aos Estados Unidos e encarava qualquer tentativa de formação de blocos regionais como uma ameaça potencial de desestabilização nas relações Brasil-Estados Unidos. O ministro deixava de considerar que aquele ambiente internacional poderia constituir um espaço de permanente negociação no âmbito do sistema de poder. No âmbito regional, ambos os países, Brasil e Argentina, adotavam, em graus distintos, políticas nacionalistas e de industrialização as quais se contrapunham em alguma medida com a política externa preconizada pelos Estados Unidos no sentido de limitação do estatismo e do nacionalismo 
econômico. É certo que os Estados Unidos admitiam que um certo desenvolvimento industrial e diversificação produtiva na América Latina fortaleceriam a influência norte-americana, impulsionando as exportações e a inversão de seus capitais. No entanto, esse desenvolvimento deveria enquadrar-se com as políticas liberais advogadas por aquele país (Rapoport e Spiguel, 2009).

Em termos de política interna Vargas percebeu, desde os anos 1930, que a industrialização seria o meio que levaria ao desenvolvimento econômico e que, por consequência, poderia colocar o Brasil na condição de líder regional. Já o ministro Neves da Fontoura perdeu de vista as articulações que poderiam ter sido feitas frente aos Estados Unidos diante do projeto de aproximação com a Argentina através do Pacto $A B C$, proposto pelo presidente Juan Domingo Perón (1895-1974). Ao que tudo indica, o ministro perdeu a oportunidade para barganhar com os norte-americanos a não adesão brasileira ao projeto de blocos regionais em troca da efetiva cooperação econômica norte-americana esperada pelo presidente Vargas. ${ }^{11}$

Essa divergência de estratégias de política externa no âmbito das relações com a nação líder do sistema, os Estados Unidos, e com a região, a Argentina, acabou por distanciar definitivamente Vargas e Neves da Fontoura, culminando na renúncia do ministroem junho de 1953, e na denúncia que faria em março do derradeiro ano de 1954, a qual nos referiremos adiante.

Em uma tentativa de amenizar a crise interna que se processava, Vargas optou por uma reforma ministerial, realizada em meados de 1953, com ênfase especial às duas pastas de cuja orientação dependia o sucesso da política governamental, ou seja, o ministério da Fazenda, para o qual foi designado um antigo colaborador de Vargas, Oswaldo Aranha, e o ministério do Trabalho, entregue a João Goulart, político petebista de fácil trânsito nas áreas sindicais. Goulart, tinha, porém, o grave inconveniente de ser extremamente suspeito aos olhos das elites políticas e de certos setores militares. Na visão destes, estaria ligado à ameaça de peronização, colocando em risco a ordem social vigente. ${ }^{12}$ Sobre isso, localizamos no arquivo do Centro de Pesquisa e Documentação de História Contemporânea do Brasil (CPDOC), uma carta anônima na qual se pronunciavam os setores oposicionistas "o Jango tem muito contato com Argentina e certamente quer manietar o Exército pela massa do povo como demonstraram os descamisados que paralisaram tudo" ${ }^{13}$, em clara referência aos movimentos grevistas no país vizinho.

A escolha de Oswaldo Aranha, por outro lado, poderia ter agradado mais a oposição, uma vez que eram conhecidas suas posições pró Estados Unidos. Entretanto, numa análise mais apurada, constatamos as diferenças de orientação do novo ministro com um dos setores oposicionistas, a UDN, preconizadora de um alinhamento incondicional aos Estados Unidos. As próprias palavras de Oswaldo Aranha revelam a diferença: "as nossas relações com os Estados Unidos, sejam quais forem as vicissitudes mundiais, os acidentes de nossa vida continental e até a conduta norte-americana para conosco, devem ser conduzidos por nós, ditados pelos nossos interesses". ${ }^{14}$

\footnotetext{
${ }^{11}$ Ver RECKZIEGEL, A.L.S. Op.cit, p. 89

${ }^{12}$ Ver SKIDMORE, Thomas. Brasil: de Getúlio a Castelo. Rio de Janeiro: Paz e Terra, 1982

${ }^{13}$ Carta anônima. CPDOC/FGV, GV 52.00.00/58.

${ }^{14}$ Conferência pronunciada por Oswaldo Aranha na Escola Superior de Guerra, 1953. CPDOC/FGV.
} 
Evidente que a falta de coesão do governo em termos de condução da política externa, foi um golpe nas pretensões nacionalistas de Vargas porque também se refletia no reforço das posições do grupo pró Estados Unidos que logo a seguir acusaria o presidente de traição nacional. ${ }^{15}$

\section{Protagonismo brasileiro e alinhamento aos Estados Unidos}

Os desacertos em termos de condução da política externa culminaram na denúncia que o ex-ministro Neves da Fontoura fez em março de 1954 de que Vargas e Perón haviam realizado um acordo secreto, à revelia do Ministério das Relações Exteriores. Tomando como prova da traição um discurso atribuído ao presidente argentino realizado na Escola Superior de Guerra em Buenos Aires datado de dezembro de 1953, Neves da Fontoura provocou uma das mais graves crises no âmbito das relações internacionais interamericanas do Brasil naquela década. Segundo o ex-ministro, Perón teria afirmado que as tratativas sobre o Pacto ABC haviam começado por ocasião da eleição de Vargas sendo que este "esteve total e absolutamente de acordo com essa ideia e em realizá-la assim que assumisse o poder". ${ }^{16}$ Ainda para Neves da Fontoura, o pronunciamento de Perón denunciava a cada parágrafo o comprometimento de Vargas com a adesão ao $A B C$ e revelava que o presidente brasileiro concordara em ter um encontro com seu colega argentino: "quando Vargas subiu ao poder, prometeu-me que nos reuniríamos em Buenos Aires ou no Rio de Janeiro e faríamos esse tratado", teria esclarecido Perón. ${ }^{17}$

Segundo o pronunciamento citado por Neves da Fontoura, Vargas teria protelado o encontro sob alegadas dificuldades na condução da política interna e, diante disso, Perón o consultou sobre a possibilidade de avistar-se primeiro com o presidente do Chile, Carlos Ibañez del Campo (1877-1960). Em 21 de fevereiro de 1953, Perón assinou com Ibañez a Ata de União Econômica Argentino-Chilena, que seria a primeira medida antes de uma futura união aduaneira entre os dois países. Esse tipo de acordo, que encetava a possibilidade de formação de um bloco regional que pudesse negociar com mais força com os Estados Unidos, gerava um crescente temor na diplomacia norte-americana. Em seguida da assinatura da Ata de Santiago, o Departamento de Estado implantou uma ativa campanha através da imprensa e dos meios diplomáticos confidenciais, a fim de neutralizar uma potencial integração econômica e política sul-americana (Morgenfeld, 2011)

Quando Neves da Fontoura veio à público denunciar as tratativas secretas do $A B C$, as quais Vargas teria aderido, Perón se encontrava novamente no Chile tentando assinar o pacto com o presidente Ibañez. Surpreendido perante a representação chilena, Perón acabou por regressar à Buenos Aires visivelmente contrariado. Ali foi procurado pelo jornalista Geraldo Rocha, desafeto de Neves, que trazia, a pedido de Vargas, um recado: de que a situação no Brasil estava muito difícil e de que ele não podia mandar no seu então ex-minis-

\footnotetext{
${ }^{15}$ Ver BANDEIRA, Moniz. Presença dos Estados Unidos no Brasil. São Paulo: Civilização Brasileira, 2007.

${ }^{16}$ FONTOURA, João Neves da. Arquivo Histórico do Rio Grande do Sul. Estudo 14, maço 20, cx 10

${ }^{17}$ FONTOURA, João Neves da. Arquivo Histórico do Rio Grande do Sul. Estudo 14, maço 20, cx 10
} 
tro. Tendo, aparentemente, aceitado a explicação do presidente brasileiro, Perón proclamara que "essa união, senhores, está em plena elaboração". ${ }^{18}$

Em termos continentais, a posse do presidente Eisenhower (1890-1969), no início de 1953, marcou certa alteração na forma de tratamento que os Estados Unidos dispensavam à região. O secretário John Foster Dulles (1888-1959) admitia que o Departamento de Estado havia descuidado da América Latina. Em escala regional, tanto Brasil, quanto Argentina passavam por complexos processos de crise econômica, com inflação e queda do poder aquisitivo da população e, principalmente, recursos reduzidos para promover a ampliação da indústria pesada em seus países.

Nesse mesmo ano, o Departamento de Estado decidiu, unilateralmente, encerrar as atividades da Comissão Mista Brasil-Estados Unidos. As concessões econômicas esperadas por Vargas tornavam-se gradativamente mais problemáticas, na mesma proporção em que a corrente antinacionalista exacerbava seus temores e críticas sobre o modelo varguista, que preconizava uma política externa com margem de relativa autonomia, negando o modelo tradicional de exportação e de associação internacional, e que agilizava a política de massas, componente fundamental da sua política interna.

O nó górdio do problema era que Vargas seguia preocupado com a forma pela qual um programa de desenvolvimento econômico nacional precisava levar em conta os sistemas políticos e econômicos mundiais. A cada passo se colocava o problema da manutenção ou do aprofundamento das rupturas externas (Iani,1988:63). A esse respeito Moniz Bandeira aponta que os serviços de inteligência norte-americanos previam que, por fracassar na obtenção dos financiamentos, o governo Vargas poderia enveredar por uma rota cada vez mais independente, em questões econômicas e que o poder de barganha vis-à-vis os Estados Unidos tornar-se-ia importante fator na política externa do Brasil, compelindo-o a estreitar relações com a América Latina, bem como a incrementar seu comércio e mesmo estabelecer relações diplomáticas com a URSS (Bandeira, 1989:39).

A dificuldade em negociar os empréstimos com os Estados Unidos, crucial para o programa de desenvolvimento brasileiro, aproximaria, de certa forma, o Brasil da Argentina. Essa estratégia em direção à nação vizinha, por si só talvez não trouxesse dividendos. Porém, enquanto elemento de pressão sobre os Estados Unidos, temerosos quanto à possibilidade de formação de blocos regionais, poderia vir a oportunizar uma espécie de troca por meio da qual, em função dos empréstimos, o Brasil manter-se-ia fiel à proposta pan-americanista. Esse ponto da política do presidente Vargas ofereceu renovada munição para os setores oposicionista, que passaram a propagar o temor da formação de uma república sindicalista, à feição peronista.

Procurando demonstrar uma margem considerável de autonomia na condução da política interna e, ao mesmo tempo, reagindo contra decisão do Eximbank de não conceder mais do que cem milhões de dólares em relação aos duzentos milhões solicitados pelo governo brasileiro e prometidos pela administração Truman, Vargas assinou o decreto-lei no. 34.839 , que restringia as remessas de lucros e dividendos em até $10 \%$ ao ano, impondo às empresas estrangeiras a obrigatoriedade de se cadastrarem na Superintendência da Moeda e do Crédito (Sumoc) como requisito para gozarem das vantagens oferecidas pelo governo. A medida sobre a remessa de lucros foi o ponto culminante da postura nacionalista. A partir daí a dissensão entre os dois modelos econômicos, os que desejavam o desenvolvimento

\footnotetext{
${ }^{18}$ FONTOURA, João Neves da. Arquivo Histórico do Rio Grande do Sul. Estudo 14, maço 20, cx 10
} 
internacionalizado (ou associado a organizações externas) e os que pretendiam acelerar o desenvolvimento independente, foi total.

A denúncia de Neves da Fontoura sobre o pacto $A B C$ data de março de 1954, portanto alguns meses depois do discurso do presidente argentino, em dezembro de 1953. Por que demorou o ex-ministro em denunciar? Justificando sua reação tardia, Neves da Fontoura alegava que teria dado um prazo para que Vargas se manifestasse sobre as calúnias de Perón, ao mesmo tempo em que esperava provas da veracidade do discurso, o que teria sido obtido através de um grupo de argentinos exilados em Montevidéu.

Confrontadas com a denúncia, as autoridades argentinas negaram a autenticidade do discurso. Apesar disso, Neves da Fontoura não tinha dúvidas de sua veracidade sob alegada coincidência de estilo de Perón e por este já ter mencionado o Pacto ABC em outras ocasiões. Alegava o ex-ministro, que, embora não houvesse prova documental da transação entre os dois presidentes, era verossímil que Vargas tivesse se comprometido com o $A B C$, disfarçado inicialmente de integração econômica. (Reckziegel, 1996)

O fato de a ligação Vargas-Perón significar para o Brasil o risco de o país transformarse em mero caudatário da Argentina era negado pelos partidários de Vargas que alegavam que "o presidente Getúlio Vargas nunca precisou da orientação do governo Perón, nem de outro qualquer governo para nortear os destinos do Brasil" ${ }^{19}$

A denúncia de Neves da Fontoura e a polêmica que se seguiu, dificultou a estratégia de Vargas e ao mesmo tempo paralisou todos os seus movimentos de defesa. A alternativa final, assim, pareceu ser seu próprio silêncio. Além de afirmar que as cartas trocadas com Perón consistiam em simples cortesia, Vargas não fez nenhuma tentativa no sentido de esclarecer as acusações feitas contra ele.

A defesa do presidente ficou a cargo do chefe da casa Civil, Lourival Fontes (18991967), que dava o caso por encerrado tomando como pressuposto principal o desmentido da Embaixada da Argentina sobre a autenticidade das declarações atribuídas a Perón, consideradas falsas. Partindo, entretanto, do princípio de que o discurso fosse autêntico, ficaria evidenciado que Vargas havia manipulado Perón. Se a verdade consistia no fato de que o Pacto $A B C$ havia sido mais um expediente no rol das manobras políticas às quais Vargas era dado, esse caso era por demais delicado para ser admitido.

Porém, o recrudescimento da campanha contra Vargas ocorreu por ocasião de novas declarações de João Neves, em abril de 1954, criando a oportunidade para um embate direto entre as facções nacionalistas e entreguistas. A UDN, com sua declarada adesão aos Estados Unidos, via no binômio Vargas-Pacto $A B C$ o pretexto para colocar em questão a idoneidade do presidente, sendo que até o impeachment foi cogitado. (Skidmore, 1982)

Mesmo não tendo sido aprovado o impeachment, as acusações sobre a conivência de Vargas com o Pacto $A B C$ significaram um golpe gravíssimo no seu já tão abalado mandato. A partir desse momento, o mutismo do presidente se intensificou. A intricada estratégia adotada por Vargas impedia qualquer explicação: como dizer que a possibilidade de adesão ao Pacto $A B C$ constituiu um lance do jogo de pressão sobre os Estados Unidos para que estes liberassem os empréstimos para o fomento do desenvolvimento industrial do Brasil? Como explicar que ao invés de pactuar com Argentina e Chile, Vargas pensava em impor a liderança brasileira na região visto ser a nação economicamente mais poderosa? Como sair desse

${ }^{19}$ Anais da Câmara, 1954, p. 136. 
emaranhado sem causar um atrito nas relações com a Argentina, de tão longa data marcadas pelo estado de rivalidade?

As contradições internas comprometeram gravemente a condução da política externa, enfraquecendo a estratégia de pressão e barganha frente ao governo norte-americano. Nesse plano de ação, Vargas poderia apoiar-se no próprio espaço criado pela Guerra Fria e na proposta de formação de um bloco de poder regional, de feição anti norte-americana. Entretanto, ignorando que desse contexto poderia advir a chance de realização da autonomia regional, setores de oposição, notadamente reunidos na UDN e na concorrente antinacionalista, ou entreguista, das Forças Armadas, desarticulou a estratégia de política externa do presidente Vargas.

No agravamento das contradições da política interna as denúncias do ex-ministro das Relações Exteriores, João Neves da Fontoura, acerca do suposto pacto entre Argentina, Brasil e Chile, o Pacto ABC. Tanto as relações com os Estados Unidos, quanto com o bloco sulamericano, em particular com a Argentina, passaram a ser mais do que um problema de política externa, mas um fator mobilizador da política interna brasileira. ${ }^{20}$

Procurando mais detidamente as razões da posição de Neves da Fontoura em pro dos negócios com os Estados Unidos em detrimento da formação de um bloco regional, chegamos ao vínculo que o ministro tinha com a Standard Oil. A gigante petroleira norte-americana vinha desde a década de 1940 em um processo de expansão de negócios na América Latina. Fazia ofensivas na área de exploração de petróleo junto aos governos brasileiro e argentino. Evidente que era perturbador para Washington a expansão das nacionalizações que se fazia em ambos os países por Perón e Vargas (Rapoport e Spiguel, 2009) Por seu turno, Neves da Fontoura era um dos diretores da Ultragaz, subsidiária da Standard Oil no Brasil, o que o tornava no mínimo suspeito na tomada de decisão acerca da política externa brasileira naquele ambiente internacional (Reckziegel,1996). Essa situação vem corroborar o que aponta Estevão de Rezende Martins quando afirma que "o Estado, ainda que permaneça sendo um ator de destaque no âmbito das relações internacionais está colocado, para fins de procedimento metódico, na perspectiva da dinâmica que articula o local, o regional e o global, extrapolando em muito a dimensão doméstica" (Martins, 2012:85).

Divisões internas projetaram-se claramente sobre a condução da política externa, a qual, examinada na perspectiva do subsistema regional, permite antever que, no centro das divergências colocava-se a questão das relações com a Argentina como um risco de retração nas relações com os Estados Unidos, na medida em que estes não aprovavam a política de blocos regionais.

\section{Protagonismo brasileiro e o bloco regional}

O jogo internacional no qual se moviam os agentes políticos governamentais foi marcado por percepções excludentes. Se, como já apontamos, o ministro Neves da Fontoura preconizava que a obtenção do papel de líder sul-americano pelo Brasil estava diretamente ligada à capacidade de interlocução com Washington, para o embaixador brasileiro em Buenos Aires, Batista Lusardo, a liderança regional deveria ser obtida primeiramente.

\footnotetext{
${ }^{20}$ Ver: MADRID, Eduardo. Argentina - Brasil. La suma del sur. Buenos Aires: CaviarBleu/ Universidad de Congreso,2003
} 
Ao atentarmos para os fatos que envolvem a nomeação de Lusardo para a embaixada em Buenos Aires, podemos evidenciar as dissenções que havia no âmbito governamental sobre a orientação das relações com a Argentina. A designação de Lusardo ocorreu em meio a resistências diversas. Se o Embaixador via de forma atraente a possibilidade de voltar a ocupar o cargo em Buenos Aires, onde gozava de excelentes relações diplomáticas e de amizade, determinados círculos políticos brasileiros opunham-se a essa nomeação, alegando que a excessiva "simpatia" de Lusardo pela Argentina poderia interferir na defesa dos interesses brasileiros. ${ }^{21}$

O ministro Neves da Fontoura apresentou resistência ao nome de Lusardo, pois considerava que, devido às estreitas relações de amizade que mantinha com Perón, seu desempenho em Buenos Aires poderia sofrer influência dos interesses locais em detrimento dos brasileiros. Preocupava o ministro, também, o fato de que a indicação de um elemento próximo a Perón poderia repercutir desfavoravelmente em relação aos Estados Unidos, que tenderiam ver a situação como uma manobra em direção à formação de alianças regionais desfavoráveis aos negócios norte-americanos. Esse, talvez, fosse para Neves da Fontoura o argumento de maior peso contra a nomeação de Lusardo: diante da suspeita de uma aliança Brasil-Argentina, os Estados Unidos retirariam seu apoio ao Brasil, que veria, então, prejudicada a possibilidade de pleitear a condição de interlocutor preferencial desse país na região.

Sintoma da articulação entre a política interna e política externa está no fato de que a nomeação do embaixador Lusardo só foi oficializada em junho de 1951, quando há muito os cargos da diplomacia brasileira já haviam sido definidos. Uma vez no cargo, o embaixador deixaria clara sua linha de atuação ao afirmar: "Argentina e Brasil tem de andar juntos. Ou se compreendem e todo o continente retratará essa compreensão, ou não se entendem e padecerão todos, no continente, desse desentendimento" 22.

Partindo desse entendimento, Lusardo passará a adotar uma política de apoio irrestrito à aproximação entre ambos os países, o que era defendido, principalmente, via implementação das relações comerciais. Atuando em outras frentes, o embaixador mediou questões referentes ao atrito entre Argentina e Uruguai Entre 1951 e 1952 houve uma série de acusações do governo uruguaio de que o governo argentino infiltrava agentes políticos em várias áreas com o propósito de expansão do que denominavam de imperialismo peronista. Lusardo foi chamado pelo governo do presidente Andrés Martínez Trueba (1884-1959) que governou o Uruguai entre 1951-1952, para mediar a situação junto a Perón (Reckziegel,1996:53). O embaixador brasileiro também atuou no processo de reaproximação entre Argentina e Estados Unidos, a partir da proposição do próprio embaixador norte-americano em Buenos Aires, Elisworth Bunker (1884-1984) para que Lusardo atuasse como intermediário: "Quiero contar con su ayuda en esta oportunidad"23. Ao que o embaixador brasileiro respondeu "Com tradicional amizade que nos une aos EUA e com poderosa alavanca do entendimento com este país, poderemos (...) muito fazer para tornar melhores as relações argentino-norte-americanas". ${ }^{24}$

\footnotetext{
${ }^{21}$ Ver: ZANATTA, Loris. La internacional justicialista. Auge y ocaso de los sueños imperiales de Perón. Buenos Aires: Sudamericana, 2013.

${ }^{22}$ Carta de Batista Lusardo a Vargas, 27.09.1951, Buenos Aires. CPDOC/FGV, GV 51.09.27/3

${ }^{23}$ Carta de Batista Lusardo a Vargas, 25.10.1952, Buenos Aires. CPDOC/FGV, GV 51.10.25/1

${ }^{24}$ Carta de Batista Lusardo a Vargas, 25.10.1952, Buenos Aires. CPDOC/FGV, GV 51.10.25/1
} 
O rumo dos acontecimentos, favoráveis, até então à atuação do embaixador Lusardo seriam alterados em fins de 1952, pela ocorrência de incidentes na fronteira com o Brasil, provocados pelo contrabando. Contra os argumentos de que os incidentes teriam conotação de ataque à soberania brasileira, Lusardo afirmava que "contrabando e violação de território continuam sendo hoje uma só coisa, quando, se melhor compreensão e mais boa vontade houvesse da parte dessa gente, já o assunto teria entrado na fase de simples repressão do contrabando." 25

Os incidentes na fronteira entre Brasil e Argentina transformam-se, assim, de um caso de polícia em atritos de ordem política, agravados não só pela "falta de compreensão e presteza de algumas autoridades responsáveis argentinas", mas pela divulgação sensacionalista que a imprensa brasileira fez sobre o assunto. A fim de acalmar os ânimos, Lusardo sugeria a instalação de uma comissão mista para examinar a origem e os pormenores dos incidentes ${ }^{26}$.

$\mathrm{Na}$ verdade, os temores de Lusardo diziam respeito ao contexto todo daquele momento. Não só os incidentes de fronteira o alarmavam, também o inquietavam as delongas na assinatura do convenio comercial com o Brasil, o que, na sua visão, poderia resultar na diminuição do já existente entendimento entre o Brasil e a Argentina. Irritado com a morosidade da consecução do acordo comercial, Lusardo advertia Vargas: "Tome ação, pois senão o fizer as relações entre Brasil e Argentina poderão ir por água abaixo."27

Lusardo insistia, pelo que se infere, em que o ponto crucial das relações com a Argentina estava calcado no intercâmbio comercial. A via de integração era, portanto, antes de ser política, econômica. Os acordos comerciais firmados entre Brasil e Argentina tinham no embaixador brasileiro um grande incentivador que via na aproximação comercial o primeiro passo para uma integração política, a qual defendia. Para Loris Zanatta, o envio de Lusardo a Buenos Aires "reativou em Perón a esperança de que um entendimento com o velho caudilho brasileiro serviria para fazer ressuscitar o $A B C$, e com ele uma federação de Estados da América que fosse capaz de fazer frente à Washington" (Zanatta,2013:301).

Nesse particular, havia profunda divergência entre o embaixador e o ministro Neves da Fontoura, que julgava que convênios como o do trigo e do café seriam uma fase preparatória para a dominação política da Argentina sobre o sul do continente. ${ }^{28}$

Os objetivos da Argentina em liderar o bloco sul, em um momento em que se falava de pactuar, apareciam, ao mesmo tempo como uma ameaça e como uma incongruência. Vargas, entretanto, não teria motivo para alarme, pois entendia que a liderança regional seria dada naturalmente a quem dominasse economicamente, o que era a pretensão brasileira. ${ }^{29}$

\footnotetext{
${ }^{25}$ Carta de Batista Lusardo a Vargas, 25.10.1952, Buenos Aires. CPDOC/FGV, GV 51.10.25/1

${ }^{26}$ Carta de Batista Lusardo a Vargas, 25.10.1952, Buenos Aires. CPDOC/FGV, GV 51.10.25/1

${ }^{27}$ Carta de Batista Lusardo a Vargas, 28.01.1953, Buenos Aires. CPDOC/FGV, GV 53.01.09/4

${ }^{28}$ Essa versão também encontrou eco no exterior. A imprensa britânica, por exemplo, manifestou-se no sentido de que "os novos tratados com a Argentina têm o propósito evidente de provocar modificações de alto relevo nas relações com os países incluídos em seu novo império". Correio do Povo. Porto Alegre. 13, março, 1954.

${ }^{29}$ Ver RAPOPORT, Mario e SPIGUEL, Claudio. Relaciones Tumultuosas. Estados Unidos y el primer peronismo. Buenos Aires: Emecé, 2009.
} 
O intenso desenvolvimento das relações exteriores argentinas como, por exemplo, o acordo comercial previsto com a URSS, a visita de Perón ao Chile, a vinda de Milton Eisenhower, irmão do presidente norte-americano, à Argentina levavam Lusardo a prevenir o presidente Vargas de que em razão do protagonismo de Perón em termos de política externa, o Brasil poderia ter dificuldades de se impor como nação líder na região.

E ainda solicitava ao presidente que prestasse atenção "às coisas verdadeiramente sérias, em vez de tanto nos preocuparmos com campanhas inúteis de imprensa." $30 \mathrm{O}$ embaixador Lusardo considerava que os ataques sistemáticos que a imprensa oposicionista ${ }^{31}$ fazia ao peronismo pudesse ser responsável pela perda de prestígio e, principalmente, da influência do Brasil na Argentina.

A denúncia do ex-ministro Neves da Fontoura, nos primeiros meses de 1954, repercutiu gravemente sobre a linha de atuação do embaixador Lusardo em Buenos Aires. Somada a isso, a falta de comunicação com Vargas o exacerbava como se constata pela correspondência na qual implorava "estou inteiramente sem notícias suas e desconheço assim seu pensamento, o seu ponto de vista sobre todos esses assuntos de magna importância! Mande-me dizer alguma coisa, escreva ou dite, mas não me deixe em suspenso!" 32

A situação do embaixador era de isolamento crescente, o que é comprovado e resumido nas suas próprias palavras quando afirmava "eu próprio sofri e estou sofrendo consequência de uma atitude que nunca consegui entender. Sem apoio do meu próprio Ministro, e sendo amigo do Presidente Perón, quem não havia de sentir-se à vontade para me atacar?" $33 \mathrm{O}$ isolamento de Lusardo levou-o à renúncia. Desgastado, deixou a embaixada em Buenos Aires passando a defender o pan-americanismo e descartando os blocos regionais e as ambições hegemônicas. Coincidiu com o enfraquecimento de Vargas. Os atritos internos, decorrentes de sua política nacionalista populista, eram substancialmente agravados pela aproximação, via acordo comercial, com a Argentina, o que levantava suspeitas de peronização do Brasil. O episódio da renúncia do embaixador Lusardo mantém-se, até certo ponto, envolto em dúvidas.

\section{Considerações Finais}

Ficou evidenciado que a definição da política externa do presidente Vargas decorria, em larga escala, dos arranjos da política interna. Desse modo as postulações de Neves da Fontoura, no sentido do boicote às ligações regionais e em especial à política de blocos autônomos, encontrou ressonância na conjuntura interna, o que acabou por dificultar a aproximação com a Argentina. A razão dos temores de Neves da Fontoura fundamentavase na desconfiança com que a comunidade internacional via o peronismo, a Terceira Posição e a política de formação de blocos regionais autônomos preconizada por Perón. Portanto, a

\footnotetext{
${ }^{30}$ Correio do Povo. Porto Alegre. 13, março, 1954.

${ }^{31}$ Praticamente toda a grande imprensa brasileira era contra Vargas, excetuando-se o jornal Última Hora, de Samuel Wainer.

${ }^{32}$ Correio do Povo. Porto Alegre. 13, março, 1954

${ }^{33}$ Carta de Batista Lusardo a Vargas ,06.07.1953, Buenos Aires. CPDOC/FGV, GV 53.07.06/1
} 
possibilidade de uma ligação mais estreita entre Brasil e Argentina seria, na sua ótica, desfavorável ao projeto de associação ao projeto de unidade continental dos Estados Unidos. Prosseguindo na defesa da política de concessões aos Estados Unidos o ex-ministro seria um dos pilares de desestruturação do governo Vargas e do recrudescimento no antagonismo das relações Brasil-Argentina.

Tem-se, então, que a diplomacia brasileira do período oscilou em torno de percepções divergentes o que foi prejudicial à afirmação de uma estratégia de política externa unívoca e capaz de colocar o país no protagonismo da região. As ações desencadeadas no âmbito externo foram elemento crucial no aprofundamento da crise com que Vargas se deparou no ano de 1954, cuja culminância foi seu suicídio, em agosto.

Os Estados Unidos, por sua vez, em documentação do Departamento de Estado, apontavam a "recusa do Presidente em definir sua posição em questões de maior importância, que por si a consequência de sua personalidade política e métodos de administrar." Reiteravam que o estilo centralizador de Vargas "deixa seus membros de Gabinete e outros importantes funcionários do governo completamente dependentes dele nos assuntos de política. Desde que nenhum funcionário pode alguma vez, mesmo em seu próprio campo, estar seguro da política global do Presidente". ${ }^{34}$ Essas impressões iam ao encontro do que ocorrera em relação ao ministro Neves da Fontoura e ao embaixador Batista Lusardo sobre os quais pode-se dizer que, de certa maneira, tatearam por si próprios percursos divergentes em relação à política externa, alheios aos intuitos do presidente Vargas, o que acabou por fragilizar a estratégia de obtenção da liderança regional.

Ao final, esperamos ter demonstrado que, no processo de reconstrução da história política desse período, o campo das relações internacionais configurou-se como locus de investigação indispensável para os historiadores estabelecerem os nexos causais em relação ao ambiente interno e externo. Admite-se que a interpretação acerca das articulações entre o interior e o exterior revela-se tarefa complexa para os estudiosos dessa área, para os quais a análise das múltiplas escalas, local, regional, global, reveste-se de importante ferramenta teórico- metodológica para a compreensão dos contextos históricos.

\section{Bibliografia}

BANDEIRA, Moniz (1989). Brasil-Estados Unidos: a rivalidade emergente (1950-1988). Rio de Janeiro: Civilização Brasileira.

DUROSELLE, Jean Baptiste (2000). Todo império perecerá. Brasília: Universidade de Brasília; São Paulo, Imprensa Oficial do Estado.

FAUSTO, Boris e DEVOTO, Fernando J. Brasil e Argentina. Um ensaio de história comparada (1850-2002) São Paulo: Editora34, 2004.

GONÇALVES, Williams (2011). Relações Internacionais. Disponível em http://www.ce-

dep.ifch.ufrgs.br/Textos Elet/pdf/WilliamsRR.II.pdf. Acesso em 20 de dezembro de 2016.

HIRST, Mônica (1985) “Vargas y Perón: las relaciones argentino-brasileñas”. Todo es História.

\footnotetext{
${ }^{34}$ Embaixada EUA. Rio de Janeiro. s/d. CPDOC/FGV, DE 50.01.23/1
} 
Buenos Aires: Ceal, n. 224, pp 9-20.

IANNI, Octavio (1988). O Colapso do Populismo no Brasil. Rio de Janeiro: Civilização Brasileira. MARTINS, Estevão de Rezende (2012). "História das Relações Internacionais". In CARDOSO, Ciro Flamarion; VAINFAS, Ricardo. Novos Domínios da História. Rio de Janeiro: Elsevier,pp73-94.

MILZA, Pierre (1996). “Política interna e política externa”. In RÉMOND, René (org). Por uma História Política. Rio de Janeiro: Editora UFRJ/FGV, pp 365-400

MORGENFELD, Leandro Ariel (2011). Vecinos en conflicto. Argentina y Estados Unidos em las Conferencias Panamericanas (1880-1955). Buenos Aires: Continente.

RAPOPORT, Mario (2002). Tiempo de crisis, viento de cambio. La Argentina y el poder global. Buenos Aires: Norma.

RAPOPORT, Mario; SPIGUEL, Claudio (2009). Relaciones Tumultuosas. Estados Unidos y el primer peronismo. Buenos Aires: Emecé.

RECKZIEGEL, Ana Luiza Setti O Pacto ABC. As relações Brasil-Argentina na década de 1950. Passo Fundo: Ediupf, 1996.

SKIDMORE, Thomas (1982) Brasil: de Getúlio a Castelo. São Paulo:

VIZENTINI, Paulo G. Fagundes (2003). Do nacional-desenvolvimentismo à Política Externa Independente (1945-1964). In FERREIRA, Jorge e DELGADO, Lucília de Almeida Neves (orgs). O Brasil republicano. O tempo da experiência democrática. Rio de Janeiro: Civilização Brasileira, p. 195-216.

WENDZEL, Robert (1985). Relações Internacionais. Brasília: Editora Universidade de Brasília.

ZANATTA, Loris (2013). La internacional justicialista. Auge y ocaso de los sueños imperiales de Perón. Buenos Aires: Sudamericana. 